\title{
Development of an e-Learning Portal for Pediatric Endocrinology: Educational Considerations
}

\author{
K. Grijpink-van den Biggelaar ${ }^{a}$ S.L.S. Drop ${ }^{a} \quad$ L. Schuwirth ${ }^{b}$ \\ a Division of Endocrinology, Department of Pediatrics, Sophia Children's Hospital/Erasmus MC, Rotterdam, and \\ ${ }^{b}$ Department of Educational Development and Research, Maastricht University, Maastricht, The Netherlands
}

\section{Key Words}

Development medical competencies · e-Learning • Adult learning $\cdot$ Assessment in competency-based learning

\begin{abstract}
Background: Global accessibility and dissemination of developments in pediatric endocrinology prompted to examine how to develop an educational interactive e-SPE web portal. Methods: A systematic approach was used to identify the relevant aspects of accessibility and dissemination. An orientation at the big idea was made, executed by an analysis of the needs of student and teacher pediatric endocrinologists, a definition of the learning objectives, a research in educational literature and an exploration of ICT design specifications. Results: The intensive collaboration between medical, educational and information technology disciplines resulted in a portal design. The portal meets requirements of adult learning, stresses interaction between partners in learning and offers direct feedback during the learning process. The portal supports the development of not only knowledge but also competences both at junior and advanced levels. Conclusion: When the e-SPE portal is completed, the options for summative assessment will be examined as a medium for international certification in conjunction with local and national requirements (http://espe. elearning.nl).

Copyright $\odot 2010$ S. Karger AG, Basel
\end{abstract}

\section{Introduction}

In pre- and postgraduate medical education, available experience and the need for adequate guidance vary so much that it seems nearly impossible to offer a study program that matches all demands. The European Society for Paediatric Endocrinology (ESPE), in collaboration with its sister societies LWPES, SLAP, and APEG, has decided to develop an e-learning portal (e-SPE portal) to satisfy educational needs of their junior and senior members. The pedagogical design is based on psychological learning theories and recent research. The most important feature of the portal is the integration of learning, instruction and assessment. The formative assessment not only offers immediate feedback to the learner but is also imbedded in daily practice. The interaction between learners and teachers in this portal supports aspirant and qualified pediatric endocrinologists in the acquisition and maintenance of their professional competencies.

Here we describe the educational considerations relevant for the development of an e-learning web portal designed to meet the current requirements for learning, teaching and assessment.

\section{KARGER}

Fax +4161306 1234 E-Mail karger@karger.ch www.karger.com
K. Grijpink-van den Biggelaar, MA

Division of Pediatric Endocrinology

Sophia Children's Hospital, Erasmus MC, PO Box 2060

NL-3000 CB Rotterdam (The Netherlands)

Tel. +31 1070 36643, Fax +31 1070 36811, E-Mail kalinka@grijpink.eu 


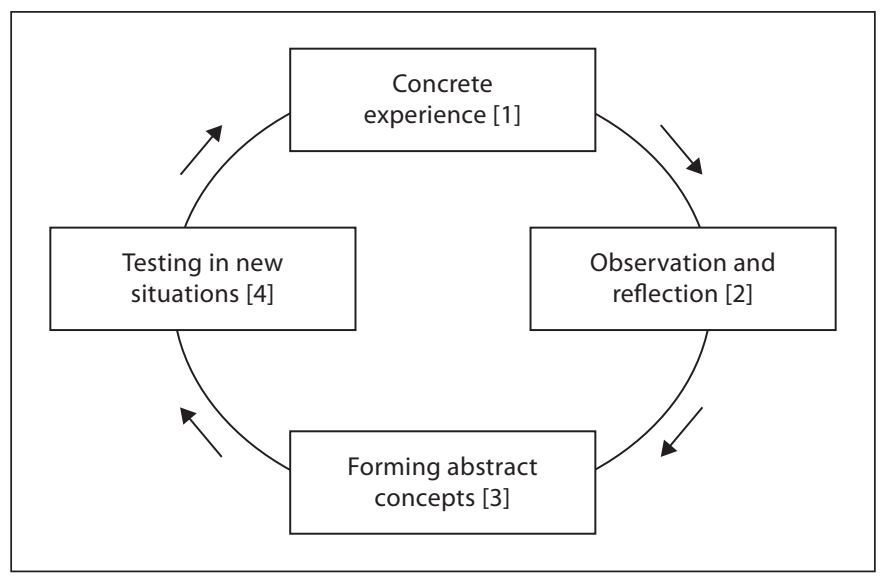

Fig. 1. The four phases in the experiential learning cycle. Each combination of two modes is suggested to be a distinct learning style: [1-2] divergence: learning by experiencing and watching, by observing, reflecting and questioning; [2-3] assimilation: learning by watching and thinking, by theorizing, making analyses and models; [3-4] convergence: learning by thinking and doing, by testing theory in practice, seeking solutions for problems; [4-1] accommodation: learning by doing and experiencing, by having hands-on and real experiences. Learning is only completed when all phases are run through [from 2].

\section{Methods}

Professionals of three disciplines were brought together to explore the big idea of a portal, representing pediatric endocrinology, medical education and information technology. A systematic design approach was used to identify the relevant aspects of accessibility and dissemination. This approach contains 5 phases: (1) Preliminary research: In this phase an orientation process took place to obtain a coherent insight in the problem. By interviewing and observing teachers and learners and by research in literature of medical education, the analysis of medical students' and teachers' needs was made. By comparing European programs of pediatric endocrinology and by studying the requirements of new developments in postgraduate medical education, a definition of the learning objectives was elicited. An intensive exploration of ICT design specifications followed; (2) Design; (3) Realization and construction; (4) Test, and (5) Implementation.

In this paper we report the insights gained in the preliminary research phase. These considerations are applied, being the theoretical scaffolds of the e-SPE portal design.

\section{Orientation at Medical Teaching and Learning}

Clinical competence and performance have to be developed during clerkships and residency. This work-based learning is equivalent to the traditional and useful apprenticeship model, but it faces several challenges: (1) Medical expertise is developing very quickly. Therefore, keeping up with the global dissemination of knowledge is a need for every doctor and resident. (2) As a result of the complexity of the hospital organization and the frequent rotations during specialty training, learning has become more difficult to arrange and to monitor. In hospital and in outpatient settings, students learn on the job, but there is no guarantee that the objectives to be studied are met [1]. (3) Like all adults, when placed in new situations, medical students and registrars have their preferences in learning. Kolb [2] places these preferences in a four-phased cycle (fig. 1) and emphasizes that learning is only completed when all four phases are completed. The question then arises how to organize a complete learning process. (4) Medical teachers are confronted with various forms of students' learning behavior. This variation is related to the degree of autonomy and dependency of the student [3]. Having the freedom to choose their own learning strategy is critical for adult learners [4]. If the medical teacher presumes that all students learn in the same way as he/she did, these crucial needs of freedom are hampered. (5) Finally, although they are very dedicated to their students, most doctors and educators are not trained in educational skills and in creating learning situations that meet characteristics of students in and outside the hospital. It is unreasonable to expect that they create a learning environment that fits all the expectations and needs of learners. Most doctors teach how they experienced their own teaching and they act on their beliefs on good teaching [5]. Moreover, teaching duties are often added to an already heavy workload [6].

\section{Learning Objectives for Pediatric Endocrinologists}

The e-SPE portal aims to offer a contribution to learning whilst meeting the challenges of teaching and learning in the clinical context. It is not a replacement for learning in the workplace; it is a component of the learning and teaching toolbox. This portal aims at supporting the learning of cognitive objectives, competencies and skills. First, the portal supports cognitive learning objectives: development of medical knowledge and problemsolving and academic skills in the area of pediatric endocrinology, as determined by the ESPE [7] in cooperation with the European Board of Paediatrics (EBP) [8]. It deals with knowledge of normal development, pathophysiological mechanisms and current interventions. Second, as outlined in further detail below, the portal assists the local training situation by contributing to the development of social-affective objectives, i.e. the development of com- 
petencies like Professional, Collaboration, Communication, Manager and Health Advocate [9]. Finally, the portal contributes to the development of technical motor skills by digital demonstrations.

\section{Target Groups}

Target groups to be served are undergraduate and advanced students, post-docs, residents, fellows, specialists, consultants, as well as an educationally underprivileged audience worldwide. Users of this portal can play different roles as learners. Independent of their level of performance, all users can work out their personal goals, not only as medical expert but also as student, instructor, assessor or colleague. This portal is an environment where users can display their continuing professional development.

\section{Educational Requirements}

The above-mentioned learning objectives and the challenges of teaching and learning in the clinical context prompted to a search in the educational literature, specifically with respect to aspects of adult learning, effective learning, and competency-oriented learning, all related to medical education and assessment.

\section{Learning from Experience}

Experience and learning needs are central in adult learning [4]. Actually, adults learn more from experience accumulated over time than from being taught. Adults seek relevant issues that are immediately applicable. In this respect, constructivist learning theories, based on the concept of building new constructs on one's personal past and current knowledge, are very useful. Personal experiences and previous conclusions are the building blocks whilst learning on the job. Acquiring knowledge is a process of actively interpreting and constructing individual knowledge representations [10].

\section{Storing and Retrieving Information}

In order to store new information successfully in the long-term memory, information has to be linked meaningfully to previously existing knowledge [11], creating a semantic network, 'a structure of illness scripts' [12]. Such a network has to be built up by meaningful experiences. Retrieval of the assumptions and hypotheses, necessary to diagnose and to manage patient cases, is achieved through activation of this semantic network. Retrieval should become independent of the specific context in which knowledge is gathered; therefore, repetition in different situations is necessary. Transfer of knowledge and problem-solving routines jumping from one situation to another is attained by extensive practice and by experience to recognize whether the concept is appropriate for this specific situation. Thus, to acquire pattern recognition, to be able to categorize and to form a concept, many experiences are necessary.

\section{Using Teachers' and Learners' Interaction}

Irby [1] recommends facilitating learning by increasing continuity-of-patient-care experiences and contact with faculty members, encouraging collaborative and self-directed learning, providing faculty development, and strengthening assessment and feedback procedures.

Anderson [13] concludes that most learning goals could be accomplished by e-learning, using some combination of online community activity and computer-supported independent study activities. In figure 2 the challenge for developers is shown to create a learning environment that is simultaneously learner-, content-, community- and assessment-centered.

\section{Involving and Preparing Adults to Learn}

Adult learners need to know what is expected, what performance is desired, to understand what will be the personally added value of the acquisition of new knowledge or skills and how this can be acquired. Adults have different reasons to be involved and to stay engaged, not only because they have different prior knowledge but also because of the requirements of the learning environment. Principles as for example active elaboration, systematic feedback and immediate application are helpful [14]. An environment which allows 'just-in-time, just enough, alternative learning paths and full learner control' could result in more effective learning [4].

\section{Assessing with Feedback}

Feedback aims at offering students more insight in their progress towards the objectives and to support students in developing learning skills. Good feedback is pivotal in the learning and assessment process. Ideally, it is given face-to-face, is concrete and aimed at identifying strengths and weaknesses and suggestions for strategies for improvement [15].

Commonly, assessment is used at the end of a learning program to make 'high-stakes' decisions whether a student does well enough to practice independently: the so- 
Fig. 2. To create online educational experiences and contexts it is important to further all types of interaction. Well known is the human interaction between student and teacher about learning content (vertical line). The student-teacher interaction can take place using a variety of synchronous or asynchronous activities such as video, audio, computer conferencing or virtual interactions. The learning activities and interactions in this figure have to be chosen in relation to the learning objectives. Although a student is never alone, there are structured learning tools associated with independent learning such as (computer-assisted) tutorials, drills, games and simulations [from 13].

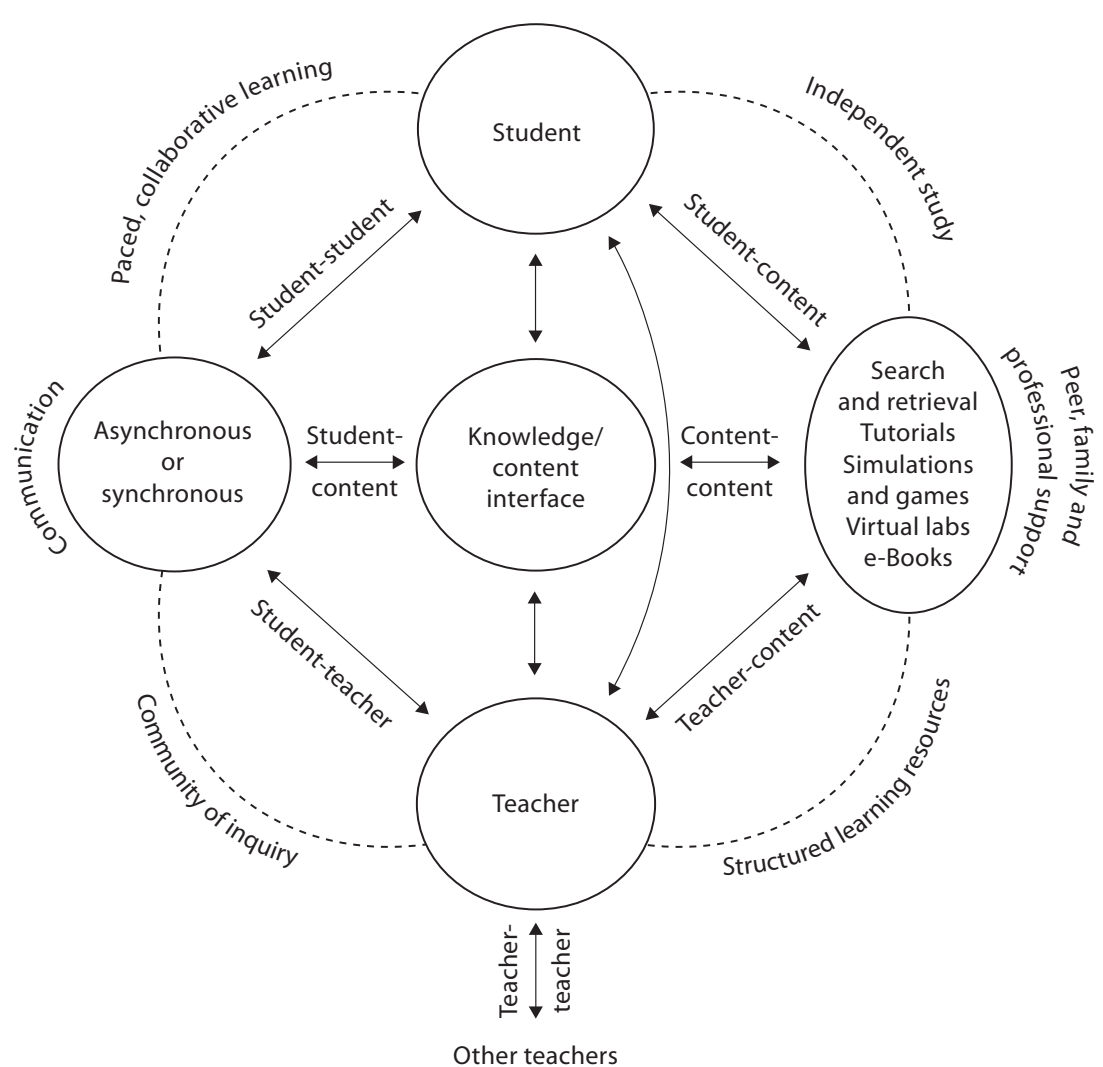

called summative assessment. In addition, however, assessment during the learning program has an important formative function. The formative part of assessment with the primary purpose to provide feedback has an important educational role [16-18].

Entirely formative assessment is not useful in the long run because it is often not taken seriously enough. On the other hand, purely summative assessment is not useful in an educational setting, because students are not involved in and informed about their own learning. In order to develop life-long learning skills, students have to gain experience in self-assessment during learning. Thus, in order to steer the learning of students, assessment has to have both a summative and a maximized formative component [19].

\section{Validating Self-Assessments}

The lack of accuracy in self-assessments makes clear that peer assessments offer important opportunities to learn from colleagues [20]. Recently, Galbraith et al. [18] made a plea for a periodic external validation of self-as- sessment results, linking the results of self-assessment to subsequent learning activities. Professional societies, such as ESPE, could play an important role by providing norm-referenced values, derived from populations of physicians with similar practice profiles and consensusbased performance standards.

Figure 3 shows the cycle of improvement, locally validated by the mentor [21] and externally validated by an external board [18].

\section{Integrating Assessment in Authentic Cases}

With reference to the educational role of formative assessment, van den Vleuten and Schuwirth [17] propose a conceptual shift to an integral programmatic approach. This perspective lightens a whole task approach, which fits in competency-based curricula. It implements assessment in the design of the learning environment. While developing the content of the program, experts and boards have to agree about the quality of performances and the specific mix of instruments to assess these. Validity of assessment can be reached by choosing the authen- 
Fig. 3. Cycle of improvement by internal and external validation [adapted from 18, 21].

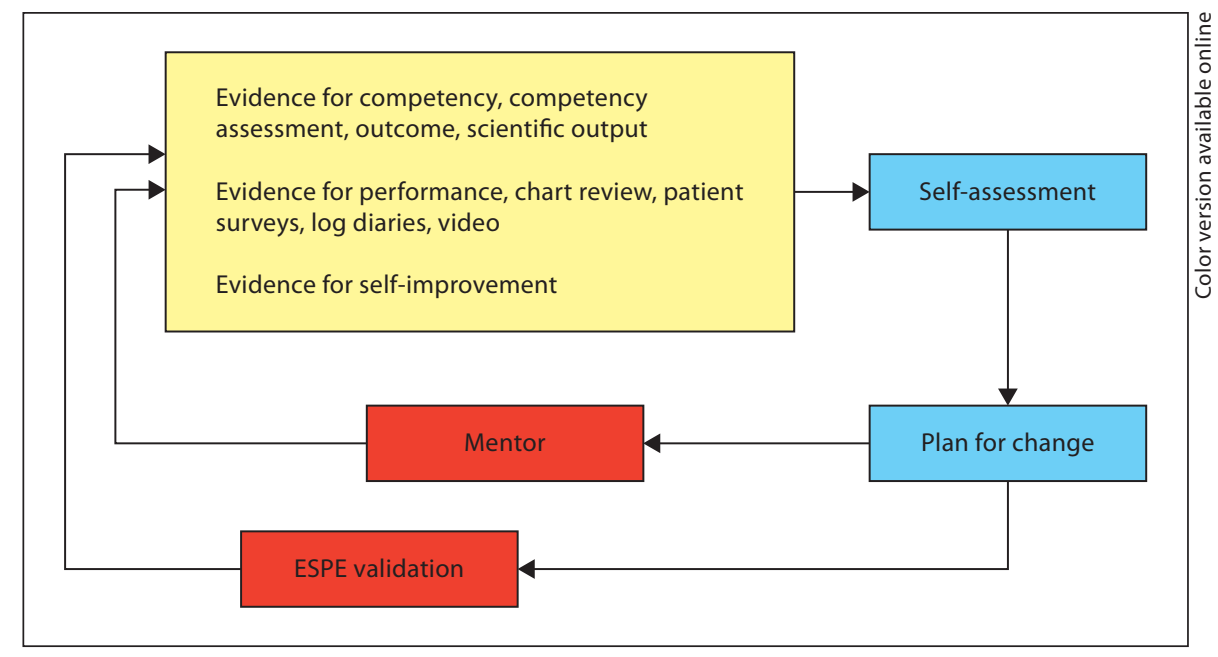

tic situations and reliability by adequate and careful sampling. As an application of this concept, Ten Cate and Scheele [22] postulate the entrustable professional activity. Entrustable professional activities cover the domain of the (sub)discipline and should be considered as critical professional activities.

\section{Assessing Competencies}

Using a copy of an authentic, realistic situation is popular in medical (under/post)graduate assessment procedures. The Objective Structured Clinical Examination (OSCE) is used to assess (under)graduates' clinical knowledge and skills. Most OSCEs assess clinical reasoning, diagnostic skills, and communication with patients. Students participate in several standardized cases, portrayed by trained standardized patients. This method of assessment is repeatedly called valid and reliable, but is attended with high costs [23].

Jefferies et al. [24] conclude that it is feasible to develop OSCE stations and checklists which incorporate the CanMEDS competencies. Prerequisites are the role descriptions and clear learning goals per (sub)specialty. To bridge the sources gap in assessment procedures, medical institutes develop virtual patients. Virtual patients are illustrated by videos, with e.g. history-taking, animations of growth processes, $\mathrm{X}$-rays, laboratory results, to allow the students practicing diagnosis, etc., and to evaluate their medical knowledge. Although also very time-consuming, the virtual case is reusable and durable [25]. The virtual patient case also guarantees regularity and reproducibility, which is an advantage compared to the actors in the OSCE.

Development of an e-Learning Portal for Pediatric Endocrinology

\section{Assessing with Reliable Feedback}

The feedback from teachers to students should be based on experts' general agreement. To attain reliable feedback, experts exchange their comments with each other. Three problems arise then. First, panels of experts may show differences in their personal performances. Experts work idiosyncratically and this may have a degradation effect on each other: they work quicker and more adequately and thereby they mention fewer actions, and thus score fewer actions [26]. Second, differences between experts frequently exist about scoring and weighing [27]. Thirdly, differences in scoring may also be due to cultural and socioeconomical differences. It is important to pay careful attention to the experts' agreement. Cascallar and Cascallar [28] suggest developing scoring guidelines for performance.

\section{Results: Design of the Portal}

According to the above-mentioned educational considerations, the portal is designed to meet the requirements for learning, teaching and assessment.

\section{Levels}

The portal offers two levels. The first core level focuses on learning content in the basic objectives of the pediatric endocrinology domain such as growth, puberty, diabetes mellitus and disorders of sex development. This level is meant for the medical student, aiming at understanding normal development and its pathophysiology with its clinical and social implications. The second advanced level deepens this content with more complicated cases and

Horm Res Paediatr 2010;73:223-230 
theory and is meant for the advanced student, e.g. the fellow. The fellow is then additionally able to analyze clinical data and to come to a diagnosis, to solve problems related to this diagnosis, to appraise scientific evidence and to communicate with professionals and patients (parents).

\section{Authentic Cases}

Cases are meaningful experiences to learn from and to create a semantic network of illness scripts. A number of well-chosen authentic cases are prepared in the portal. Students will be invited to bring in comparable cases, in order to enhance the transfer of knowledge and to repeat the exchange of knowledge.

\section{Collaborative Learning}

Collaborative learning is an important feature of the portal, replacing the social contacts students normally value in classes. In the 'Forum', users create or work out a case together, help each other with diagnosis and the best solution, ask to criticize each other's mistakes in reasoning, compare and evaluate and while collaborating, might discover new possibilities. In this way, knowledge and experience develop into complex constructs.

\section{Feedback}

Senior endocrinologists are responsible for the control of students' case production in their role as members of the editorial board. These experts also provide feedback on assignments and writings and stimulate the students to respond. The students can contact an expert or the Forum with their own questions. This feedback on cases creates a way of hands-of learning that is instructive and avoids risks for the patient.

\section{Teacher-Learner Interaction}

While the teachers are developing standards, grinding their teeth how to give feedback, discussing what is a good performance while executing a task, questioning if the case follows evidence-based medicine, the students learn at all Miller's stages: knows, knows how, shows how and does [29].

\section{Theory and Library}

The portal is learner orientated; the user makes choices in case, level, and way of learning and support. For a better understanding, for literature check and for the use of theory there is a library, called the 'Mediclopedia', consisting of an alphabetically-ordered list of relevant subjects with links and chapters. The students can use the strategy they prefer: starting with theoretical informa- tion or with a specific case. Otherwise they stop the case to look for additional just-in-time information, e.g. by the use of videos, animations and simulations.

\section{Monitoring and Assessing Learning}

In response to the need of systematic and immediate feedback during the learning process, the e-SPE portal allows the learners to test their understanding with questions and assignments. The answers will be stored in a personal logbook. With the logbook the learners have an overview of their results and an instrument to reflect on their learning. They may decide to repeat a subject or to step over to a higher cognition level.

\section{Technique of Assessment}

This portal intends to use more types of assessment, aligned with the goals. Instruments are the multiplechoice question, with varying numbers of options and computerized short-answer questions, for which a combo box to type in the answer is used. The answer will be matched with a list of possible answers. The portal stores answers in a logbook and immediately presents the results. If the portal is used as a learning environment, the student receives immediate feedback. If used as an examination environment, students have a complementary tool to demonstrate their competencies.

Complex questions and assignments are to be sent to and checked by experts (table 1). Although we may assume that specifically post-doctoral students (such as subspecialty fellows) are more interested in learning than in copying, Royce [30] recommends to use fraud detection programs, e.g. Safe Assign, Ephorus and Turn-it-in.

\section{Final Assessment and Certification}

After completion of the portal, i.e. when a satisfying coverage of the domains is attained, the options for summative assessment will be examined as a medium for certification, in strong relationship with the other methods of assessments, and local and national requirements.

\section{Conclusion}

With the development of this portal, entrance is given to a learning environment that allows users to gain, share, contribute, disseminate, assess and develop knowledge in an accessible and flexible way. This combination of processes will offer a possibility for interactive learning, instruction and assessment at a global level. 
Table 1. Abbreviated example of an interactive case assessing various competencies

\begin{tabular}{lll}
\hline Competence Question & Assessment \\
\hline
\end{tabular}

You are a fellow pediatric endocrinologist and you receive a call from a pediatrician who asks your advice: Mrs. Johnson has just given birth to her second child. The pediatrician is concerned about the infant's genital development, as it is unclear whether the child is a boy or a girl

Medical expert What information do you need from the pediatrician?

Medical expert What information is relevant to provide to the pediatrician?

Collaborator What is your advice to the pediatrician?

Communicator What is your advice to the pediatrician to tell the parents? What to tell family and friends?
Multiple-choice question

Open question, provide correct items

Open question, feedback provided by expert

Open question, feedback provided by expert

The genitalia of the otherwise healthy infant indeed look very ambiguous

Medical expert What information regarding the physical examination are you specifically interested in? What further information needs to be collected and what tests need to be performed after the initial physical examination?

Multiple-choice question$$
\text { ultiple-choice question }
$$

The karyotype is 46,XX; based on hormonal and ultrasound investigations you diagnose congenital adrenal hyperplasia Medical Expert Deficiency of which enzyme is most likely responsible? Multiple-choice question

Situation A: Both parents are very relieved that they have a girl and the mother says: 'From the beginning, I had the feeling that I had a daughter!'

Communicator You discuss this condition with the infant's parents. What do you Open question, feedback provided by expert say?

Situation B: Both parents are very disappointed and angry. They consider the genitalia rather masculinized and do not go along with the conclusion of the tests that the baby is a girl

Professional How would you handle this situation and what do you say to the Open question, feedback provided by expert parents?

The baby girl is treated with gluco- and mineralocorticoids. At 3 months of age the parents ask whether the genitals will remain masculinized and whether surgery is indicated

Scholar In the recent literature, pros and cons have been voiced regarding early genital surgery. Which arguments are most relevant for you?

Open question, feedback provided by expert Explain why.

Eve is seen regularly at the outpatient clinic. The dosage of her substitution medication is adjusted as needed

Medical expert Which measures are relevant in judging the adequacy of the

Multiple-choice question

dosage of hydrocortisone?

Medical expert Which measures are relevant in judging the adequacy of the Multiple-choice question dosage of mineralocorticoids?

The parents would like to have more children

Communicator What do you offer them in terms of genetic counseling?

Scholar In the recent literature, there are pros and cons with regard to prenatal diagnostics and treatment. Which arguments are most relevant for you? Explain why.

When Eve is 16 years of age she sends you an e-mail stating that she has a boyfriend and she asks you to explain once more in understandable terms what kind of disorder she has

Communicator Specifically she asks you what happened when she was born, whether she was first a boy, why she had operations, if she could

Open question, feedback provided by expert get children and if she should take medication all her life. Prepare this letter.

Scholar Search for explanations for the lower fertility rates reported for women with treated congenital adrenal hyperplasia. Search for comparable or competitive articles published in the last 5-7 years.
Open question, feedback provided by expert Open question, feedback provided by expert
Open question, feedback provided by expert 
The evaluation and adjustment of the content and assessment will continuously be on the developers' agenda, not only because of the accountability to the ESPE council and sponsors, but mainly as issues concerning development of a portal are scarcely examined. Although characteristics of this portal are based on theoretical insights, we have to realize that practice will offer surprises. The proof of the pudding is in the eating.

\section{Acknowledgements}

The research leading to these results has received funding from the European Community's Seventh Framework Program (FP7/2007-2013) under grant agreement No. 2014444. The authors gratefully acknowledge the financial support of the European Society for Paediatric Endocrinology and unrestricted educational grants from Sandoz International, Holzkirchen, Germany, and Eli Lilly \& Co., Indianapolis, Ind., USA.

\section{References}

1 Irby DM: Teaching and learning in ambulatory care settings: a thematic review of the literature. Acad Med 1995;70:898-931.

2 Kolb AD: Learning and problem-solving: on management and the learning process; in Kolb AD, et al (eds): Organizational Psychology. New York, Prentice-Hall, 1974.

- 3 Vermunt JD, Verloop N: Congruence and friction between learning and teaching. Learn Instruct 1999;9:257-280.

4 Knowles MS, Holton EF III, Swanson RA: The Adult Learner. The Definitive Classic in Adult Education and Human Resource Development, ed 6. London, Elsevier, 2005.

5 Willcoxson L: The impact of academic learning and teaching preferences on their teaching practice; a pilot study. Stud High Educ 1998;23:59-70.

6 Ramani S: Twelve tips to promote excellence in medical teaching. Med Teach 2006;28:1923.

7 European Society for Paediatric Endocrinology (ESPE), 2006 (http://www.eurospe. org/).

8 European Board of Paediatrics (EBP): European training syllabus in paediatric endocrinology and diabetes, Swedish version, 2006 (http://www.eurospe.org/education/education_training.html).

9 Royal College of Physicians of Surgeons of Canada: CanMEDS project, 2000, 2005 (http://rcpsc.medical.org/canmeds/index. php).

10 Jonassen D: Objectivism versus constructivism: do we need a new philosophical paradigm? Educ Technol Res Dev 1991;39:5-14.
1 Regehr G, Norman GR: Issues in cognitive psychology: implications for professional education. Acad Med 1996;71:988-1001.

$\checkmark 12$ Schmidt HG, Boshuizen HPA: On acquiring expertise in medicine. Educ Psychol Rev 1993;5:205-221.

13 Anderson T: Toward a theory of online learning (2). (http://epe.lac-bac.gc.ca/100/200/ 300/athabasca_univ/theory_and_practice/ ch2.html).

14 Bergenhenegouwen GJM EAM, Tillema HH: Strategisch opleiden in organisaties. Deventer, Kluwer Bedrijfswetenschappen, 1992.

15 Orrel J: Feedback on learning achievement: rhetoric and reality. Teach High Educ 2006; 11:441-456.

16 Gibbs G, Simpson C: Conditions under which assessment supports students' learning. Learn Teach High Educ 2004;5:3-31.

17 Van den Vleuten CPM, Schuwirth LWT: Assessing professional competency: from methods to programmes. Med Educ 2005;39: 309-317.

18 Galbraith M, Hawkins RE, Holmboe ES: Making self-assessment more effective. J Cont Educ Health Prof 2008;28:20-24.

19 Schuwirth LWT, van den Vleuten CPM: A plea for new psychometric models in educational assessment. Med Educ 2006;40:296300 .

20 Violato C, Lockyer J: Self and peer assessment of pediatricians, psychiatrists and medicine specialists: implications for selfdirected learning. Adv Health Sci Educ Theory Pract 2006;11:235-244.

21 Schuwirth LWT: Measuring and maintaining the quality of our students and doctors. Current developments in assessment. Invited address at the ESPE steering committee meeting, Brussels, 28 February 2006.
22 Cate OT, Scheele F: Competency-based postgraduate training: can we bridge the gap between theory and clinical practice? Acad Med 2007;82:542-547.

23 Rudland J, Wilkinson T, Smith-Han K, Thompson-Fawcett M: You can do it late at night or in the morning. You can do it at home, I did it with my flatmate. The educational impact of an OSCE. Med Teach 2008; 30:206-211.

24 Jefferies A, Simmons B, Tabak D, McIlroy H, Lee KS, Roukema H, Skidmore M: Using an objective structured clinical examination to assess multiple physician competencies in postgraduate training. Med Teach 2007;29: 181-191.

25 Choules AP: The use of e-learning in medical education: a review of the current situation. Postgrad Med J 2007;83:212-216.

26 Ericsson KAC N: Expert performance. Am Psychol 1994;49:725-747.

27 Swanson DB, Norcini JJ, Grosso LJ: Assessment of clinical competence: written and computer-based simulations. Assess Eval High Educ 1987;12:220-246.

28 Cascallar A, Cascallar E: Setting standards in the assessment of complex performances: the optimized extended response setting method; in Segers M, Dochy F, Cascallar E (eds): Optimizing New Methods of Assessment: In Search of Qualities and Standards. Dordrecht, Kluwer Academic, 2003.

29 Miller GE: The assessment of clinical skills/ competence/performance. Acad Med 1990; 65(suppl):S63-S67.

30 Royce J: Plagiarism: keeping up with the cheats. A bibliography (http://park.robcol. k12.tr/jroyce/plagbibl2.html). 